P-ISSN: 2615-1723

E-ISSN: 2615-1766

April 2020
Jurnal Riset Pendidikan Dasar

03 (1), (2020) 8-16

Submitted: Januari, Accepted Februari, Published: April

\title{
PENGARUH PENERAPAN MODEL PEMBELAJARAN TALKING STICK TERHADAP PENINGKATAN HASIL BELAJAR MATEMATIKA DI SEKOLAH DASAR
}

\author{
Andi Ardhila Wahyudi ${ }^{*}$, Hamdana Hadaming ${ }^{2}$ \\ 1,2 Program Studi Pendidikan Guru Sekolah Dasar, Fakultas Keguruan dan Ilmu Pendidikan, \\ Universitas Muhammadiyah Makassar, Indonesia \\ Korespondensi. *E-mail: andiardhila@gmail.com
}

\begin{abstract}
Abstrak
Penelitian ini bertujuan untuk mengetahui pengaruh pembelajaran matematika melalui penerapan model pembelajaran Talking Stick di Sekolah Dasar dengan materi penjumlahan terhadap siswa kelas 1 SD Negeri No 9 Bone-Bone Kabupaten Takalar. Desain penelitian ini adalah pra-experiment design dengan jenis one group pretest-posttest design yaitu sebuah experiment yang dalam pelaksanaannya melibatkan satu kelas sebagai kelas eksperimen. Adapun cara pengambilan sampel yaitu dengan sampling jenuh. Populasinya adalah siswa kelas 1 SD Negeri No 9 Bone-Bone Kabupaten Takalar sebanyak 27 siswa.Adapun teknik pengumpulan data dalam penelitian ini yaitu tes dan observasi. Hasil dalam penelitian menunjukkan bahwa skor rata-rata hasil belajar matematika materi penjumlahan di kelas 1 SD Negeri No 9 Bon-Bone Kabupaten Takalar sebelum penerapan model pembelajaran Talking Stick diperoleh hasil 64,81 sedangkan setelah dilaksanakan perlakuan dengan penerapan model pembelajaran Talking Stick dengan materi yang sama di peroleh skor rata-rata 80,74. Sehingga dapat disimpulkan terjadi peningkatan hasil belajar siswa kelas 1 SD Negeri No 9 Bon-Bone Kabupaten Takalar dengan nilai rata-rata Gain ternomalisasi 0,51 terdapat dalam kategori sedang.
\end{abstract}

Kata Kunci: Model pembelajaran Talking Stick; Penjumlahan; Hasil belajar.

\section{THE EFFECT OF APPLYING THE TAKING STCIK LEARNING MODEL TO THE IMPROVEMENT OF MATHEMATICS LEARNING OUTCOMES IN ELEMENTARY $S C H O O L$}

\begin{abstract}
This study aims to determine the effectiveness of mathematics learning through the application of the Talking Stick learning model in elementary schools with the summing material for grade 1 students of SD Negeri No 9 Bone-Bone Takalar Regency. The design of this research is pre-experiment design with one group pretest-posttest design, that is an experiment which in its implementation involves one class as an experimental class. The sampling method is saturated sampling. The population is grade 1 students at SD Negeri No. 9 Bone-Bone Takalar Regency with 27 students. The data collection techniques in this study are tests and observations. The results in the study showed that the average score of mathematics learning outcomes in addition material in grade 1 SDN No. 9 Bon-Bone Takalar Regency before the application of the Talking Stick learning model obtained 64.81 results whereas after the treatment was carried out with the application of the Talking Stick learning model with material the same is obtained an average score of 80.74. So it can be concluded an increase in student learning outcomes in grade 1 SD Negeri 9 Bon-Bone Takalar Regency with an average value of 0.51 nominated gain is in the medium category.
\end{abstract}

Keywords: Talking Stick learning model, addition, learning outcomes

Copyright (C2020, JRPD, ISSN 2615 - 1723 (Print), ISSN 2615 - 1766 (Online) 


\section{PENDAHULUAN}

Diera globalisasi saat ini pendidikan sangatlah penting untuk semua orang. Karena pendidikan merupakan upaya yang dilakukan secara sadar dan terencana untuk mencerdaskan dan mengembangkan potensi murid melalui kegiatan bimbingan, pengajaran, atau latihan sebagai bekal di masa yang akan datang. Pendidikan seharusnya wajib diterima bagi setiap individu, karena dengan adanya pendidikan, setiap individu dapat mengembangkan potensinya, karakter dan jenjang hidupnya menjadi lebih baik.Pendidikan secara umum mempunyai arti yaitu suatu proses kehidupan dalam mengembangkan diri tiap individu untuk dapat hidup dan melangsungkan kehidupan. Sehingga menjadi seorang yang terdidik itu sangat penting.Pendidikan pertama kali kita dapatkan yaitu di lingkungan keluarga, lingkungan sekolah dan lingkungan masyarakat. Sebagaimana tercantum dalam Undang-Undang No. 20 Tahun 2003 tentang Sistem Pendidikan Nasional BAB I Pasal 1 (2004, hlm. 2).

Undang-undang diatas mengandung arti bahwa pendidikan dilaksankan dengan tujuan agar siswa dapat mengembangkan potensi dirinya untuk kehidupan yang akan datang melalui suasana belajar dan proses pembelajaran yang aktif dan inovatif. Tahap pendidikan dimulai dari jenjang pendidikan dasar, menengah, dan tinggi diberikan kepada murid sesuai dengan tingkat perkembangan.

Pendidikan sekolah dasar juga merupakan pendidikan permulaan yaitu 12 tahun wajib belajar.Jenjang pendidikan di sekolah dasar merupakan jenjang pendidikan yang mendasar bagi siswa untuk membuka wawasannya dan memegang peranan penting untuk meningkatkan kualitas sumber daya manusia dimasa yangakan datang.Keberhasilan seorang siswa dalam proses pembelajaran dikarenakan adanya peranan penting seorang guru. Proses pembelajaran atau kegiatan belajar-mengajar di kelas tidak bisa lepas dari keberadaan seorang guru. Tanpa adanya guru pembelajaran akan sulit dilakukan, apalagi dalam rangka pelaksanaan pendidikan formal. Guru memiliki peran yang paling aktif dalam pelaksanaan pendidikan demi mencapai tujuan pendidikan yang hendak dicapai.Tujuan pendidikan yang tercantum dalam Permendiknas No. 41 Tahun 2007 dalam standar proses.

Salah satu mata pelajaran yang diajarkan di sekolah dasar, yang berorientasi pada pengembangan kemampuan belajar murid adalah mata pelajaran Matematika.Menurut Nasution dalam bukunya Isrok'atun dan Amelia Rosmala (2018:3) mengungkapkan kata matematika berkaitan dengan bahasa Sanskerta yaitu "medha" atau "widya" yang artinya kepandaian, ketahuan, dan intelegensi. Berdasarkan beberapa penjelasan istilah matematika tersebut maka dapat di pahami bahwa matematika merupakan suatu ilmu yang mempelajari bagaimana proses berpikir secara rasional dan masuk akal dalam memperoleh konsep. Matematika dikatakan sebagai suatu ilmu karena keberadaannya dapat dipelajari dari berbagai fenomena.

Pembelajaran matematika tanpa melibatkan siswa secara aktif mengakibatkan sebagian besar siswa menjadi pasif dan kurang antusias dalam proses pembelajaran.Kebiasaan bersikap pasif dalam pembelajaran mengakibatkan sebagian besar siswa takut dan malu bertanya pada guru mengenai materi yang kurang dan belum dipahami, sehingga hasil belajar kurang optimal.

Berdasarkan hasil observasi awal yang dilakukan di kelas I SDN No.9 Bone-Bone Kecamatan Pattallassang Kabupaten Takalar pada mata pelajaran matematika materi penjumlahan terdapat beberapa masalah diantaranya, siswa masih lebih banyak bermain, bercerita dengan teman sebangkunya serta beberapa masih pasif dan tidak mandiri selama proses belajar mengajar sehingga hasil

Copyright (2020, JRPD, ISSN 2615 - 1723 (Print), ISSN 2615 - 1766 (Online) 


\section{Jurnal Riset Pendidikan Dasar, 03 (1), April 2020 (8-16)}

Andi Ardhila Wahyudi, Hamdana Hadaming

belajar murid belum mencapai kriteria ketuntasan minimal (KKM) yang ditetapkan yaitu 70. Dari jumlah murid 32 orang, yang masih berada dibawah KKM sebanyak 59, $37 \%$ (19 orang murid) dan yang sudah melewati KKM sebanyak 40,62\% (13 orang murid). Hal ini di akibatkan karenaterdapat beberapa masalah yang diduga sebagai penyebab belum optimalnya pencapaian hasil belajar murid, yaitu proses pembelajaran di kelas tersebut berlangsung hanya sebatas guru menerangkan dan murid mendengarkan kemudian mencatat yang diberikan sehingga keterlibatannya sangat rendah, media yang digunakan dalam pembelajaran hanya sebatas papan tulis, tidak terdapat kegiatan belajar yang menarik seperti memberikan permainan, hanya sebagian kecil siswa yang bertanya atau mengutarakan pendapatnya jika ada hal-hal yang belum dimengerti terkait dengan materi yang diberikan.Ketika guru bertanya tidak ada satupun murid yang menjawab.Dan pada kenyataannyabanyak siswa yang terlihat malas, tidak percaya diri mengerjakan soalsoal latihan dan hasil belajar yang kurang memuaskan.Hal itu terjadi karena belum adanya variasi penggunaan model pembelajaran yang dilakuakan oleh guru.

Model pembelajaran Talking Stick menurut Miftahul Huda (2018: 225) memiliki manfaat mampu menguji kesiapan siswa, melatih keterampilan mereka dalam membaca dan memahami materi pelajaran dengan cepat,dan mengajak mereka untuk terus siap dalam situasi apapun. Serta model ini cocok digunakan untuk semua kelas dan semua tingkatan umur.Beberapa penelitian terkait dengan model pembelajaran talking stick yaitu salah satunya dilaksanakan pada murid kelas VIII SMP Negeri 15 Kendari pada tahun 2015 yang dilakukan oleh Sitti Mardiana melalui penerapan model pembelajaran Talking Stickterjadi peningkatan hasil belajar.Talking Stickadalah model pembelajaran yang dilakukan dengan bantuan sebuah tongkat, siswa yang memegang tongkat wajib menjawab pertanyaan dari guru setelah siswa mempelajari materi. Suprijono (2013: 110) menyatakan bahwa kelebihan model pembelajaran Talking Stick yaitu a) Melatih murid membaca dan memahami materi dengan cepat b) Memacu murid lebih giat dalam belajar c) Murid berani mengemukakan pendapat d) Model pembelajaran ini membuat murid ceria, senang, dan melatih mental siswa untuk siap pada kondisi dan situasi apapun.

Dengan mencermati persoalan yang dipaparkan diatas, peneliti mencoba mengadakan penelitian dengan harapan tujuan dari pembelajaran matematika padamateri penjumlahan dapat tercapai dengan baik dan dapat membuat murid aktif belajar dan meningkatkan hasil belajarnya.

\section{METODE}

Jenis penelitian ini adalah penelitian eksperimen, yaitu metode penelitian yang digunakan untuk mencari pengaruh perlakuan tertentu terhadap yang lain dalam kondisi yang terkendalikan (Sugiono 2015:107). Desain dalam penelitian ini merupakan penelitian preeksperimental designs jenis One-Group PretesPosttest Design yaitu memberikan tes sebelum perlakuan (pretest) dan setelah perlakuan (posttest). Dalam penelitian ini hasil perlakuan dapat diketahui lebih akurat, karena dapat membandingkan dengan keadaan sebelum diberi perlakuan (treatment). Adapun desain penelitian ini adalah sebagai berikut:

\section{$\mathrm{O}_{1} \mathrm{X} \mathrm{O}_{2}$}

Sumber: (Sugiyono, 2015:111)

Gambar 1 One-Group Pretes-Posttest

\section{Keterangan:}

O1 = Nilai sebelum perlakuan (pretest)

O2 = Nilai setelah perlakuan (posttest)

$\mathrm{X}=$ Perlakuan dengan menggunakan model Talking Stick

Model eksperimen ini melalui tiga langkah yaitu:

Copyright (C2020, JRPD, ISSN 2615 - 1723 (Print), ISSN 2615 - 1766 (Online) 


\section{Jurnal Riset Pendidikan Dasar, 03 (1), April 2020 (8-16)}

Andi Ardhila Wahyudi, Hamdana Hadaming

a) Memberikan pretest untuk mengukur variabel terikat (hasil belajar penjumlahan) sebelum perlakuan dilakukan.

b) Memberikan perlakuan kepada kelas subjek penelitian dengan menerapkan model pembelajaran Talking Stick

c) Memberikan posttest untuk mengukur variabel terikat setelah perlakuan.

Tabel 1 Teknik Kategorisasi Standar Ketuntasan Hasil Belajar

\begin{tabular}{ccc}
\hline No & Skor & Kategori \\
\hline $\mathbf{1}$ & $0 \leq \mathrm{X}<55$ & Sangat Rendah \\
$\mathbf{2}$ & $55 \leq \mathrm{X}<70$ & Rendah \\
$\mathbf{3}$ & $70 \leq \mathrm{X}<80$ & Sedang \\
$\mathbf{4}$ & $80 \leq \mathrm{X}<90$ & Tinggi \\
$\mathbf{5}$ & $90 \leq \mathrm{X} \leq 100$ & Sangat Tinggi \\
\hline
\end{tabular}

Sumber :SDN No.9 Bone-Bone

Populasi dalam penelitian ini adalah siswa kelas I SDN No.9 Bone-Bone Kecamatan Pattallassang Kabupaten Takalar. Dalam penelitian ini sampelnya terdiri dari semua populasi kelas I SDN No.9 Bone-Bone Kecamatan Pattallassang Kabupaten Takalar yang berjumlah 27 siswa, terdiri dari siswa laki-laki 11 orang dan siswaperempuan 16 orang.

Instrumen yang digunakan dalam penelitian ini adalah tes hasil belajar matematika yang sudah dikumpulkan, untuk mengukur hasil belajar matematika siswa setelah pembelajaran matematika dengan model pembelajaran Talking Stick.Untuk memperoleh data mengenai hasil belajar matematika siswa, dengan menggunakan teknik pemberian tes hasil belajar.Untuk menganalisis data yang diperolehdari hasil penelitian akan digunakan analisisstatistik deskriptif dan inferensial.

Analisis deskriptif digunakan untuk menganalisis data yaitu hasil belajar siswa, Analisis Data Hasil Belajarsiswa Dalam Pembelajaran Matematika.Data hasil belajar yang telah terkumpul akan dianalisis secara kuantitatif dengan menggunakan analisis statistik deskriptif. Statistik deskriptif yang di gunakan adalah tabel distributif frekuensi,variasi rata-rata dan standar deviasi.Statistikinidigunakan untuk mengungkapkan keadaan sampel atau mendeskripsikan hasil belajar siswa.

Kriteria seorang siswa dikatakan tuntas belajar apabila memenuhi Kriteria Ketuntasan Minimun (KKM) yang ditetapkan oleh sekolah yaitu 70 .

Tabel 2 Kategorisasi Standar Ketuntasan Hasil Belajar Matematika siswa

\begin{tabular}{cc}
\hline Nilai & Kriteria \\
\hline $\mathbf{0} \leq \mathbf{x}<\mathbf{7 0}$ & Tidak Tuntas \\
$\mathbf{7 0} \leq \mathbf{x} \leq \mathbf{1 0 0}$ & Tuntas \\
\hline
\end{tabular}

Ketuntasan klasikal tercapai apabila minimal $75 \%$ siswa dikelas tersebut telah mencapai Kriteria ketuntasan minimal (KKM) yaitu $\geq 70$.

$$
\begin{gathered}
\text { Ketuntasan belajar klasikal }= \\
\frac{\text { banyaknya siswa dengan skor } \geq 70}{\text { banyaknya murid }} \times 100 \%
\end{gathered}
$$

Analisis Data Peningkatan Hasil Belajar (N-Gain)siswa Dalam Pembelajaran Matematika. Untuk mengetahui peningkatan (Gain) hasil belajar matematika pada kelas eksperimen dengan menggunakan Gain.Gain diperolehdengan cara membandingkan hasilPretest dan Posttest. Gain yang diperoleh untuk menghitung peningkatan hasil belajar matematika murid adalah menggunakan gain ternormalisasi (Normalisasi gain).

Analisis statistik inferensial digunakan untuk menguji hipotesis penelitian dengan menggunakan uji-t. Sebelum melakukan pengujian hipotesis terlebih dahulu peneliti melakukan uji normalitas sebagai uji Prasyarat.

\section{HASIL DAN PEMBAHASAN}

Untuk mengetahui pengaruh pembelajaran matematika melalui model pembelajaran Talking Stick pada siswa kelas I SDN No.9 Bone-Bone Kecamatan Pattallassang Kabupaten Takalar, dilakukan prosedur penelitian dan analisis data hasil 
Jurnal Riset Pendidikan Dasar, 03 (1), April 2020 (8-16)

Andi Ardhila Wahyudi, Hamdana Hadaming

penelitian dengan menggunakan teknik analisis deskriptif dan teknik analisis inferensial.Hasil analisis keduanya diuraikan sebagai berikut.

\section{Hasil Analisis Deskriptif}

Hasil analisis statistik deskriptif menunjukkan tentang distribusi skor hasil belajar sebelum dan sesudah pembelajaran dengan melalui penerapan model pembelajaran Talking Stick, sekaligus masalah yang dirumuskan dalam penelitian yaitu analisis ketuntasan hasil belajar siswa, terhadap penerapan model pembelajaran Talking Stick.Berikut deskripsi dari hasil penelitian yang telah dilakukan di SDN No.9 Bone-Bone Kecamatan Pattallassang Kabupaten Takalar

a. Deskripsi Hasil Belajar Matematika

1) Deskripsi Hasil Belajar Matematika siswa kelas I SDN No.9 Bone-Bone Sebelum pemberian perlakuan (Pre-Test)

Untuk memberikan gambaran awal tentang hasil belajar matematika siswakelas I yang dipilih sebagai sampel penelitian. Berikut disajikan skor hasil belajar matematika siswa kelas I, sebelum pemberian perlakuan (pretest).

Berdasarkan tabel 3 dapat dinyatakan bahwa skor rata-rata hasil belajar matematika sebelum penerapan model pembelajaran Talking Sick dari27 siswa sebesar 64,81 dengan standar deviasi 16,184 dan skor ideal 100 masih berada pada kategori rendah berdasarkan kategorisasi hasil belajar siswa. Jika hasil belajar siswa dikelompokkan ke dalam lima kategorisasi standar ketuntasan hasil belajar sebelum perlakuan maka diperoleh distribusi frekuensi dan presentase dapat dilihat pada tabel 4 .

Tabel 3 Statistik Skor Hasil pre-tes

\begin{tabular}{cc}
\hline Statistik & Nilai Statistik \\
\hline Ukuran sampel & 27 \\
Skor ideal & 100 \\
Skor maksimum & 93 \\
Skor minimum & 40 \\
Rentang skor & 53 \\
Rata-rata (mean) & 64,81 \\
Median & 60 \\
Modus & 60 \\
Standar Deviasi & 16.184 \\
Variansi & 262,234 \\
\hline
\end{tabular}

Pada tabel 5 dapat ditunjukkan bahwa dari 27 siswa kelas I SDN No.9 Bone-Bone Kecamatan Pattallassang Kabupaten Takalar, siswa yang memperoleh skor pada kategori sangat rendah 7 siswa (25.9\%), kategori rendah 8 siswa(29.6\%), kategori sedang 6 siswa $(22.2 \%)$, kategori tinggi 4 siswa $(14.8 \%)$, dan kategori sangat tinggi 2 siswa (7.4\%). Setelah skor rata-rata hasil belajar siswa sebelum perlakuan bahwa 27 siswadikonvesi kedalam lima kategori diatas, maka rat-rata hasil belajar matematika siswakelas I SDN No.9 Bone-Bone Kecamatan Pattallang Kabupaten Takalar sebelum diajarkan melalui model pembelajaran Talking Stick masih tergolong rendah.

Tabel 4 Distribusi Frekuensi Dan Presentase Skor Hasil pretest

\begin{tabular}{ccccc}
\hline No. & Skor & Kategori & Frekuensi & $\begin{array}{c}\text { Presentase } \\
(\%)\end{array}$ \\
\hline 1. & $0 \leq \mathrm{X}<55$ & $\begin{array}{c}\text { Sangat } \\
\text { Rendah }\end{array}$ & 7 & $25.9 \%$ \\
2. & $55 \leq \mathrm{X}<70$ & Rendah & 8 & $29.6 \%$ \\
3. & $70 \leq \mathrm{X}<80$ & Sedang & 6 & $22.2 \%$ \\
4. & $80 \leq \mathrm{X}<90$ & Tinggi & 4 & $14.8 \%$ \\
5. & $90 \leq \mathrm{X} \leq 100$ & Sangat & 2 & $7.4 \%$ \\
\hline
\end{tabular}

Selanjutnya skor hasil belajar sebelum kriteria ketuntasan minimum (KKM) dapat diberikan perlakuan dikategorikan bedasarkan dilihat pada Tabel 5 .

Copyright C2020, JRPD, ISSN 2615 - 1723 (Print), ISSN 2615 - 1766 (Online) 
Tabel 5 Deskripsi Ketuntasan Hasil Belajar Matematika siswa Sebelum perlakuan (pretest)

\begin{tabular}{cccc}
\hline Skor & Kategori & Frekuensi & Presentase (\%) \\
\hline $\mathbf{0} \leq \mathbf{x}<\mathbf{7 0}$ & Tidak Tuntas & 15 & $55,60 \%$ \\
$\mathbf{7 0} \leq \mathbf{x} \leq \mathbf{1 0 0}$ & Tuntas & 12 & $44,40 \%$ \\
\hline
\end{tabular}

Kriteria seorang siswa dikatakan tuntas hasil belajar matematikanya apabila memiliki nilai paling kurang 70. Dari tabel 6 diatas bahwa jumlah siswa yang tidak memenuhi kriteria ketuntasan adalah 15 siswa $(55,60 \%)$ dan memenuhi kriteria ketuntasan minimum adalah 12 siswa (44,40\%). Berdasarkan deskripsi diatas dapat ditarik kesimpulan bahwa hasil belajar murid kelas I SDN No.9 BoneBone Kecamatan Pattallassang Kabupaten Takalar masih belum memenuhi ketuntasan belajar klasikal yaitu hanya $44,40 \%$ dari $100 \%$ siswa.

2) Deskripsi Hasil Belajar Matematika siswa Setelah perlakuan (Post-Test).

Berikut dijelaskan deskripsi dan presentase skor hasil belajar matematika siswa kelas I SDN No.9 Bone-Bone Kecamatan Pattallassang Kabupaten Takalar, setelah perlakuan atau setelah menerapkan model pembelajaran Talking stick (Post-Test).

\begin{tabular}{|c|c|c|}
\hline \multirow[t]{2}{*}{ Tabel 6} & \multicolumn{2}{|c|}{$\begin{array}{l}\text { Statistik Hasil Belajar Matematika } \\
\text { siswa Setelah perlakuan (post test) }\end{array}$} \\
\hline & Statistik & Nilai Statistik \\
\hline & kuran sampel & 27 \\
\hline & Skor ideal & 100 \\
\hline & or maksimum & 100 \\
\hline & zor minimum & 53 \\
\hline & Rentang skor & 47 \\
\hline & ta-rata (mean) & 80,74 \\
\hline & Median & 83,00 \\
\hline & Modus & 83 \\
\hline & andar Deviasi & 12,990 \\
\hline & Variansi & 168,738 \\
\hline
\end{tabular}

Berdasarkan tabel 6 dapat dinyatakan bahwa skor rata-rata hasil belajar matematika setelah pemberian perlakuan dengan penerapan model pembelajaran Talking Sick dari27 siswa sebesar 80,74 dengan standar deviasi 12,990 dan skor ideal 100 berada pada kategori tinggi berdasarkan kategori hasil belajar siswa. Jika hasil belajar siswa dikelompokkan kedalam lima kategorisasi hasil belajar maka diperoleh distribusi frekuensi dan presentase sebagai berikut:

Tabel 7 Distribusi Frekuensi dan I SDN No.9 Bone-Bone Setelah perlakuan (post test)

\begin{tabular}{|c|c|c|c|c|}
\hline No. & Skor & Kategori & Frekuensi & Presentase (\%) \\
\hline $\mathbf{1 .}$ & $0 \leq \mathrm{X}<55$ & Sangat Rendah & 1 & $3.7 \%$ \\
\hline $\mathbf{2 .}$ & $55 \leq \mathrm{X}<70$ & Rendah & 3 & $11.1 \%$ \\
\hline 3. & $70 \leq \mathrm{X}<80$ & Sedang & 6 & $22.2 \%$ \\
\hline $\mathbf{4 .}$ & $80 \leq \mathrm{X}<90$ & Tinggi & 10 & $37.0 \%$ \\
\hline $\mathbf{5 .}$ & $90 \leq \mathrm{X} \leq 100$ & Sangat Tinggi & 7 & $25.9 \%$ \\
\hline
\end{tabular}

Berdasarkan tabel 8 dapat ditunjukkan bahwa dari 27 siswa kelas I SDN No.9 BoneBone Kecamatan Pattallassang Kabupaten Takalar, siswa yang memperoleh skor sangat rendah 1 siswa (3.7\%), kategori rendah 3 siswa (11.1\%), kategori sedang 6 siswa(22.2\%), kategori tinggi 10 siswa (37.0\%), dan kategori sangat tinggi terdapat 7 siswa $(25.9 \%)$. Sehingga Skor rata-rata hasil belajar siswasetelah pemberian perlakuan denganpenerapan model pembelajaran Talking Stick bahwa 27 siswa dikonvensi kedalam lima kategorisasi hasil belajar diatas, maka rata-rata hasil belajar siswa kelas I SDN No.9 BoneBone Kecamatan pattallassang Kabupaten Takalar setelah diajarakan melalui model pembelajaran Talking Stick tergolong pada kategori tinggi.Ini juga terlihat selama proses Copyright @2020, JRPD, ISSN 2615 - 1723 (Print), ISSN 2615 - 1766 (Online) 


\section{Jurnal Riset Pendidikan Dasar, 03 (1), April 2020 (8-16)}

Andi Ardhila Wahyudi, Hamdana Hadaming

pembelajaran berlangsung saat penerapan model pembelajaran Talking Stick siswa terlihat antusias dan termotivasi untuk mengikuti pembelajaran sehingga terjadi pengaruh yang signifikan pada hasil belajarnya khususnya pada mata pelajaran Matematika SD Kelas 1.

Penelitian ini sesuai denganRahayu, S., dkk.(2018) mengatakan bahwa penerapan model cooperative learning tipe talking stick dapat meningkatkan motivasi belajar siswa.Menurut iwan, dkk (2016) keunggulan talking stick adalah "pertanyaan yang fokus pada materi pelajaran, menguji kesiapan siswa, memotivasi keberanian dan keterampilan siswa,memupuk tanggung jawab dan kerja sama, mengajarkan mengeluarkan pendapat sendiri, agar siswa berpikir sendiri apa jawaban dari pertanyaan tersebut dan mengasah kemampuan dan pengalaman siswa".

Selanjutnya skor hasil belajar setelah diterapkan model pembelajaran Talking Stick pada siswa kelas I SDN No.9 Bone-Bone dikategorikan berdasarkan kriteria ketuntasan minimum (KKM) dapat dilihat pada tabel 8 berikut:

Tabel 8 Deskripsi Ketuntasan Hasil Belajar siswa Setelah perlakuan (post test)

\begin{tabular}{|c|c|c|c|}
\hline Skor & Kategori & Frekuensi & Presentase (\%) \\
\hline $\mathbf{0} \leq \mathbf{x}<\mathbf{7 0}$ & Tidak Tuntas & 4 & $15 \%$ \\
\hline $\mathbf{7 0} \leq \mathbf{x} \leq \mathbf{1 0 0}$ & Tuntas & 23 & $85 \%$ \\
\hline
\end{tabular}

Berdasarkan tabel 9 diatas bahwa jumlah siswa yang tidak memenuhi kriteria ketuntasan minimum adalah 4 siswa $(15 \%)$ dan yang memenuhi ketuntasan minimum adalah 23 siswa (85\%). Berdasarkan deskripsi diatas dapat ditarik kesimpulan bahwa setelah pemberian perlakuan dengan penerapan model pembelajaran Talking Stick diperoleh hasil belajar matematika siswa kelas I SDN No.9 Bone-Bone Kecamatan Pattallassang Kabupaten Takalar telah memenuhi ketuntasan belajar klasikal yaitu $85 \%$ dari $100 \%$ siswa. Sehingga dengan penerapan model ini dapat meningkatkan hasil belajar matematika siswa kelas 1 SDN No 9 BoneBone.

\section{Hasil Analisis Inferensial}

Analisis statistik inferensial pada bagian ini digunakan untuk pengujian hipotesis yang telah dirumuskan dan sebelum melakukan uji-t maka terlebih dahulu dilakukan uji normalitas dan uji gain dengan menggunakan SPSS versi 16.

Hasil analisis statistik inferensial menunjukkan bahwa skor rata-rata hasil belajar murid setelah diterapkan model pembelajaran Talking Stick tampak nilai $\mathrm{t}_{\text {hitung }}>\mathrm{t}_{\text {tabel }}$ dimana $t_{\text {hitung }}=4.296 \mathrm{dan} t_{\text {tabel }}=1.706$ menunjukkan bahwa rata-rata hasil belajar murid setelah penerapan model pembelajaran Talking Stick lebih besar dari 70. Ini berarti $\mathrm{H}_{0}$ ditolak dan $\mathrm{H}_{1}$ diterima. Rata-rata gain ternormalisasi pada siswa kelas I SDN No.9 Bone-Bone Kecamatan Pattallassang Kabupaten Takalar lebih tinggi dari 0.30 yaitu 0,51 ini berarti $\mathrm{H}_{0}$ ditolak dan $\mathrm{H}_{1}$ diterima yakni gain ternormalisasi hasil belajar murid berada pada kategori sedang. Untuk ketuntasan secara klasikal tampaknilai $Z_{\text {hitung }}>Z_{\text {tabel }}$ dimana $Z_{\text {hitung }}=1,72$ dan $Z_{\text {tabel }}=$ 1,645. Ini berarti $\mathrm{H}_{0}$ ditolak dan $\mathrm{H}_{1}$ diterima yakni secara klasikal hasil belajar matematika murid kelas I SDN No.9 Bone-Bone Kecamatan Pattallassang Kabupaten Takalar setelah penerapan model pembelajaran Talking Stick memenuhi kriteria ketuntasan klasikal.

Hal ini sesuai dengan hasil penelitian yang dilakukan sebelumnya, Andreyani Y, dkk (2014) bahwa dengan menggunakan model talking stick dapat meningkatkan aktivitas belajar peserta didik. Aktivitas belajar peserta didik terbagi menjadi aktivitas fisik, aktivitas mental dan aktivitas emosional.Pada siklus I nilai rata-rata kemampuan pendidik melaksanakan pembelajaran sebesar 2,57 dengan kategori cukup dan pada siklus II nilai rata-rata mengalami peningkatan menjadi 3,55 dengan kategori baik sekali. 


\section{Jurnal Riset Pendidikan Dasar, 03 (1), April 2020 (8-16)}

Andi Ardhila Wahyudi, Hamdana Hadaming

Pada model pembelajaran Talking Stick menempatkan siswa dalam posisi sebagai pusat pembelajaran, murid diberi kesempatan untuk menggali pengetahuan dan menemukan konsepnya sendiri terkait dengan materi yang dipelajari. Pemahaman terhadap suatu konsep pembelajaran akan terlihat dari kecepatanya menerima pelajaran dan memecahkan permasalahan yang diberikan.

Berdasarkan penelitian yang dilakukan penulis dan penelitian oleh Andreyani Y, dkk (2014) yang memberi kesimpulan hasil belajar matematika meningkat setelah penerapan model pembelajaran Talking Stick. Maka dapat disimpulkan bahwahasil belajar matematika siswa setelah penerapan model pembelajaran Talking Stick memiliki pengaruh dalam meningkatkan hasil belajar siswa.

\section{SIMPULAN}

Berdasarkan hasil analisis data penelitian dan pembahasan yang telah diuraikan sebelumnya, maka dapat ditarik kesimpulan bahwa pembelajaran matematika meningkat dan terdapat pengaruh dalam proses pembelajaran siswa terlihat lebih aktif dan termotivasi dengan pemberian perlakuan penerapan model pembelajaran Talking Stick pada siswa kelas I SDN No.9 Bone-Bone Kecamatan Pattallassang Kabupaten Takalar yang ditinjau dari ketuntasan hasil belajar, setelah mengikuti model pembelajaran Talking stick.

Hasil belajar siswa kelas I SDN No.9 Bone-Bone Kecamatan Pattallassang Kabupaten Takalar setelah pembelajaran melalui model pembelajaran Talking Stick termasuk dalam kategori tinggi yaitu denagn nilai rata-rata 80,74 dan standar deviasi 12,990. Hasil ini menunjukkan bahwa terdapat 23 siswa (85\%) yang tuntas dan 4 siswa(15\%) yang tidak tuntas dimana murid yang memperoleh skor sangat rendah 1 siswa (3.7\%), kategori rendah 3 murid (11.1\%), kategori sedang 6 murid (22.2\%), kategori tinggi 10 siswa $(37.0 \%)$, dan kategori sangat tinggi 7 siswa (25.9\%). Dari hasil tersebut ketuntasan hasil belajar secara klasikal telah terpenuhi $(>75 \%)$ dengan presentase hasil belajar klasikal $85 \%$. Untuk nilai gain ternormalisasi sebesar 0,51 berada pada kategori sedang.

Dalam proses pembelajaran sebaiknya pendidik harus melakukan inovasi yang baru dalam pembelajaran dengan mencoba menerapkan beberapa model-model pembelajaran yang menyenangkan untuk siswa sekolah dasar.

\section{DAFTAR PUSTAKA}

Andreyani, Y. (2014).Peningkatan Aktivitas Belajar Peserta Didik Menggunakan Model Talking Stick IPS Kelas VI di SD. Jurnal Pendidikan dan Pembelajaran Khatulistiwa. 3(4)

Departemen Pendidikan Nasional, (2007).Peraturan Menteri Pendidikan

Nasional Nomor 41 tahun 2007, tentang Standar Proses, Jakarta: Depdiknas.

Iwan. (2016). Penerapan model Pembelajaran Kooperatif Tipe Talking Stick untuk Meningkatkan Minat dan Hasil Belajar Biologi Siswa pada Materi Pencemaran Lingkungan XA di SMA Yapis Manokwari. Jurnal PancaranPendidikan5(1), 1-12.

Huda, M. (2018). Model-model pembelajaran. Yogyakarta: Pustaka Pelajar.

Isrok'atun \& Amelia, R. (2018). Model-Model Pembelajaran Matematika. Jakarta: PT Bumi Aksara

Mardiana,S. (2015). Pengaruh model pembelajaran talking stick terhadap hasil belajar matematika siswa kelas VIII Smp Negeri Kendari Pada materi Copyright (C2020, JRPD, ISSN 2615 - 1723 (Print), ISSN 2615 - 1766 (Online) 
Jurnal Riset Pendidikan Dasar, 03 (1), April 2020 (8-16)

Andi Ardhila Wahyudi, Hamdana Hadaming

lingkaran. Jurnal Pendidikan

Matematika, 3 (3), 125-138.

Permendiknas no.41 tahun 2007 tentang

tujuan pendidikan nasional.

Rahayu, S. (2018). Penerapan Model Cooperative Learning Tipe Talking Stick untuk Meningkatkan Motivasi Belajar Siswa. Pedadidaktika Jurnal Ilmiah Mahasiswa Pendidikan Guru Sekolah Dasar, 5 (1), 308-318.

Suprijono, A. (2013). Cooperative Learning Teori Dan Aplikasi PAIKEM. Yogyakarta: Pustaka Pelajar.

Sugiono.(2015). Metode Penelitian Pendidikan Pendekatan Kuantitatif, Kualitatif Dan R\&D. Bandung: Alfabeta.

Sundayana, R. (2016). Statistika Penelitian Pendidikan. Bandung: Alfabeta.

Undang-Undang RI No. 20 Tahun 2003 Tentang Sistem Pendidikan Nasional. (2004). Surabaya: Karina. 